\title{
182. The First Instance of Hemoglobin $E$ in a Japanese Family
}

\author{
By Susumu Shibata, ${ }^{*)}$ Iwao Iuchi, ${ }^{*)}$ and \\ Howard B. HAMILTON**) \\ (Comm. by Taku KomaI, M.J.A., Dec. 12, 1964)
}

The prevalence of hemoglobinopathies is well known among the people living in the South-Sea Area of Asia; of these, hemoglobin E is the most common. ${ }^{1}$ The trait is common in Thailand and Burma, and less so in the Philippines and Formosa; in the former countries it occurs frequently in combination with thalassemia. In Japan more than 120,000 people have been examined for hemoglobinopathies, and by these surveys as many as twenty kinds of abnormal hemoglobins, ${ }^{2}$ as well as thalassemia minor ${ }^{3)}$ have been discovered. However, until recently, not a single case of hemoglobin $\mathrm{E}$ has been reported in Japan.

In October, 1963 a survey for hemoglobinopathies in the Nagasaki area in Kyushu was conceived and carried out by us. About two thousand blood samples***) were collected from people of presumably pure Japanese ancestry in and around that city. In one of these samples a slow-moving hemoglobin was found which was subsequently demonstrated in the blood of several members of the proband's family. This hemoglobin was studied in detail chemically in our laboratory, and its identity with hemoglobin $\mathrm{E}$ was established.

The proband is a 33-year old apparently healthy man showing no abnormality in routine hematological tests. His hemolysate yielded on agar gel electrophoresis $(\mathrm{pH} 8.6)^{4)}$ two hemoglobin bands, $\mathrm{Hb} \mathrm{A}$ and a slow moving component whose migration was similar to $\mathrm{Hb} \mathrm{A}_{2}$ or $\mathrm{Hb} \mathrm{E}$ (Fig. 1). The slow-moving hemoglobin could be easily separated electrophoretically (either by agar-gel, paper, starch-gel or by a starch-block method $)^{5,6)}$ from $\mathrm{Hb} \mathrm{A}$ in an alkaline medium, but was difficult to separate from the latter on the cathode side in a neutral

*) Department of Clinical Pathology, Yamaguchi Medical College, Ube.

**) Clinical Laboratories, Atomic Bomb Casualty Commission, HiroshimaNagasaki. The Commission is a field research agency of the National Academy of Sciences, National Research Council, with financial support from the US Atomic Energy Commission, and is administered in co-orporation with the National Institute of Health of the Japanese Ministry of Health and Welfare.

***) Obtained from subjects seen in the Medical Clinic of the Atomic Bomb Casualty Comission in Nagasaki.

This investigation was supported in part by a PHS research grant (GM 09469-03) from the Division of General Medical Sciences, U. S. Public Health Service. 


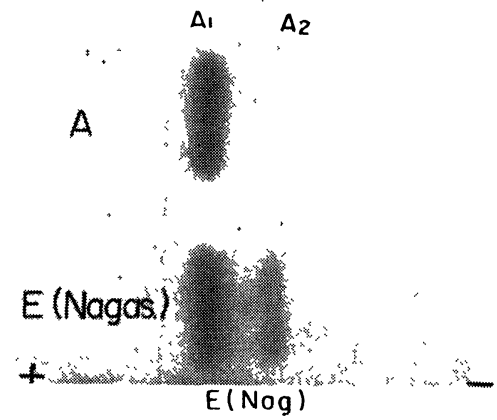

Fig. 1. Starch gel electrophoresis of the hemolysates. A: Normal subject. E (Nagas): Proband with a slow-moving hemoglobin.

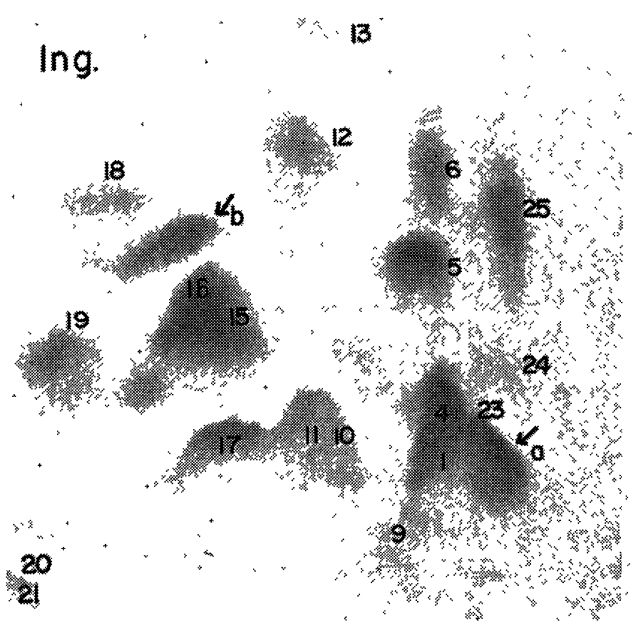

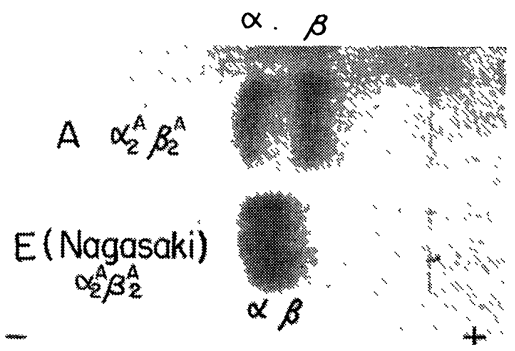

Fig. 2. Urea dissociation paper electrophoresis of the globin of the purified abnormal hemoglobin. $\alpha$ : $\alpha$ chain. $\beta$ : $\beta$ chain.

Bag.

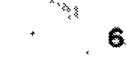

Fig. 3. Fingerprints of the purified abnormal hemoglobin. Ing.: Ingram's fingerprint. Bag.: Baglioni's fingerprint. Arrows indicate the abnormal peptide spots ("a" and " $b$ ").

or acid medium. It followed $\mathrm{Hb} \mathrm{A}$ on Amberlite IRC $50^{7)}$ or carboxymethyl cellulose ${ }^{8)}$ column chromatography. Singer's test ${ }^{9)}$ for $\mathrm{Hb} \mathrm{F}$ was within normal limits $(0.66 \%)$; the solubility of reduced hemoglobin ${ }^{5)}$ was also normal (101\%). The content of abnormal hemoglobin in the hemolysate was 24 per cent in the proband, with variation from 22 to 27 per cent in some other members of the family.

Hybridization test and urea dissociation paper electrophoresis ${ }^{11}$ of the abnormal hemoglobin purified by starch block electrophoresis showed a $\beta$-chain anomaly (Fig. 2). In accordance with this finding, the fingerprint ${ }^{12)}$ of the trypsin digest of the globin showed the absence of spot No. $26(\beta \mathrm{Tp}-3)^{13)}$ and the presence of two abnormal spots, namely, spot "a" lying to the anode side of, and below the position of spot No. 23, and spot "b" situated in the center of a tri- 
angular area circumscribed by spots Nos. 15-16, 18, and 19 (Fig. 3). Spot "b" was always clearly delineated, being isolated from those surrounding it, but spot "a" fell partially on spot No. 23 on Ingram's fingerprinting, ${ }^{12)}$ and could be completely dissociated from the latter only by Baglioni's fingerprint method. ${ }^{13)}$ Accordingly, the peptides of spot " $a$ " and spot " $b$ " were collected from Baglioni's and Ingram's fingerprints, respectively, for hydrolysis with acid for the examination of their amino acid composition.

One dimensional high voltage paper electrophoresis and Brenner's silicate thin-layer chromatography ${ }^{14)}$ of the acid hydrolysate of spot "a" peptide disclosed the presence of Asp, Glu, Val, Gly, and Lys; no other amino acid was demonstrated. Spot "b" peptide was com-

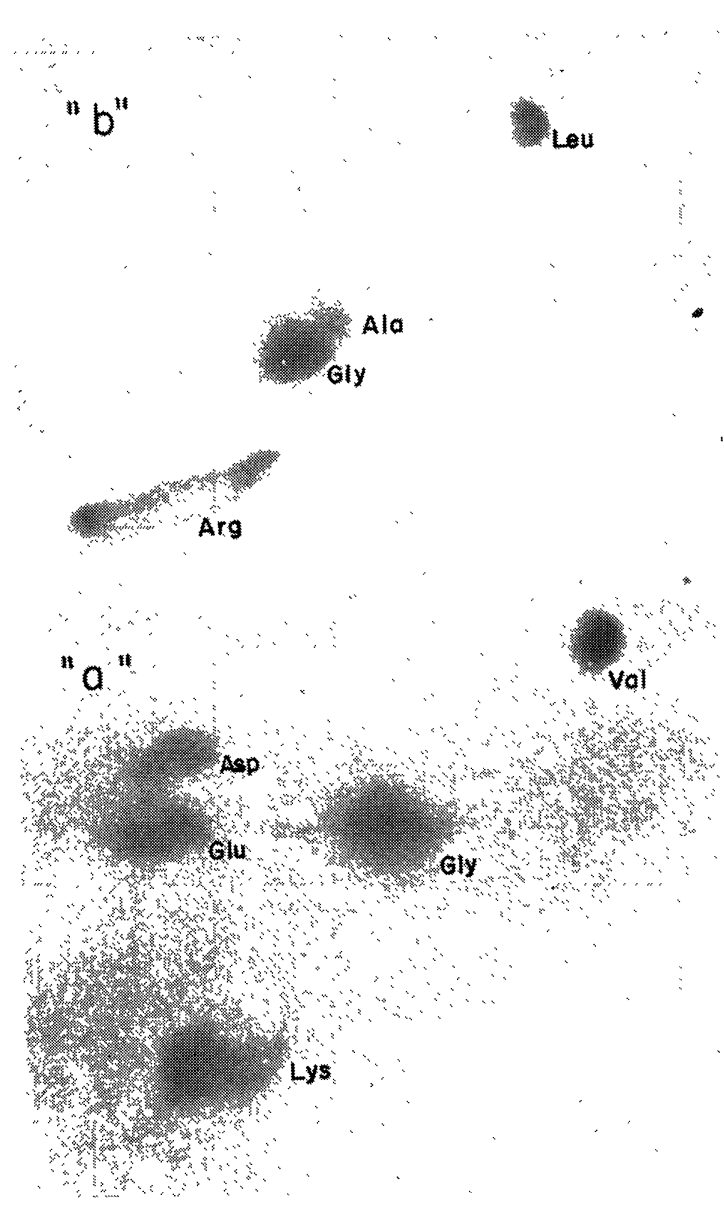
posed of Leu, Ala, Gly, and Arg, exclusively (Fig. 4); the presence of Arg was confirmed by 8-hydroxyquinoline test. ${ }^{15)}$ It is obvious from the results of the chemical analysis described above, that the slow-moving hemoglobin has a $\beta$-chain anomaly directly related to an amino acid substitution in the third tryptic peptide ( $\beta \mathrm{Tp}-3)$.

Fig. 4. Amino acid analysis (silicate thin layer chromatography) of the acid hydrolysates of spot "a" peptide and spot "b" peptide.

Comparison of the amino acid composition of spot " $b$ " peptide (Ala, Leu, Gly, and Arg) with the amino acid sequence of the normal $\beta \quad \mathrm{Tp}-3\left(\mathrm{Val} \cdot \mathrm{AspNH} \mathrm{H}_{2} \cdot \mathrm{Val} \cdot \mathrm{Asp} \cdot \mathrm{Glu} \cdot \mathrm{Val} \cdot \mathrm{Gly} \cdot \mathrm{Gly} \cdot \mathrm{Glu} \cdot \mathrm{Ala} \cdot \mathrm{Leu} \cdot\right.$ 
$29 \quad 30$

Gly $\cdot(\mathrm{Arg})^{16)}$ shows that this peptide corresponds to the tail-end of $\beta \mathrm{Tp}-3$, which is composed of the $27 \mathrm{th}$ through the 30 th residues. In addition, it is very likely that spot "a" peptide is a fragment of $\beta$ Tp-3 made of the 18th-25th amino acid residues with Lys attached at its tail-end, since the " $a$ " peptide possesses only those amino acids necessary to make up this fragment $\left(\mathrm{Val} \cdot \mathrm{AspNH} \cdot \mathrm{Val} \cdot \mathrm{Asp} \cdot \mathrm{Glu} \cdot \mathrm{Val}_{2}\right.$. $24 \quad 25$

Gly.Gly) plus Lys. The above findings are summarized in the following table.

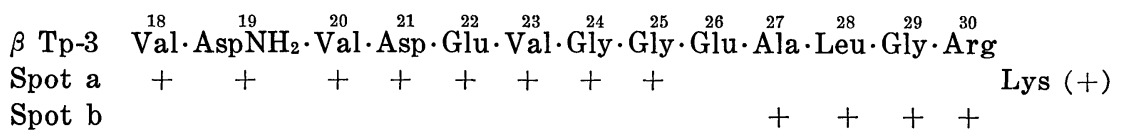

It is evident from this table that, if Lys is substituted for Glu (26), the resultant abnormal $\beta \mathrm{Tp}-3$ could give rise to two peptide fragments corresponding to the spot " $a$ " and spot " $b$ " peptides on trypsin digestion, since by this treatment the long peptide would be split at the site of lysine, exposing its $\mathrm{C}$ terminal. No other conceivable substitution is consistent with the formation of the peptides of spot "a" and " $b$ ". It is therefore concluded that in the $\beta$-chain of this slow-moving hemoglobin, Lys is substituted for Glu (26). Therefore, the hemoglobin may be expressed by the formula $\alpha_{2}^{\mathrm{A}} \beta_{2}^{26 L y s}$, which corresponds exactly with the formula for $\mathrm{Hb} \mathrm{E}$ established by Hunt and Ingram (1959). ${ }^{17)}$

Since separation of $\mathrm{Hb} \mathrm{E}$ from $\mathrm{Hb} \mathrm{\textrm {A } _ { 2 }}$ in the hemolysate is difficult, contamination of purified $\mathrm{Hb} \mathrm{E}$ with $\mathrm{Hb} \quad \mathrm{A}_{2}$ may occasionally take place, and on a fingerprint map the spot " $a$ " peptide may be mixed with No. 26 peptide ( $\delta \mathrm{Tp}-3)$ of $\mathrm{Hb} \mathrm{A}_{2}$. In our experiment, however, this possibility is excluded, because Ala which characterizes the head fragment (Nos. 18-25) of $\delta \mathrm{Tp}-3^{18)}$ in comparison with $\beta$ Tp-3 was not demonstrable in the acid hydrolysate of spot " $a$ ". The absence of Ala also contradicts the likelihood of a $\delta$-chain anomaly for this hemoglobin. Spot " $b$ " is characteristic of $\mathrm{Hb}$ E. A few years ago, a slow-moving hemoglobin closely resembling $\mathrm{Hb} \mathrm{E}$ was discovered in Kyushu and named $\mathrm{Hb}$ Miyada. The chemistry ${ }^{19)}$ of this hemoglobin, however, seems to be different from that of $\mathrm{Hb}$ E.

The pedigree of this family is shown in Fig. 5. For the last three generations all individuals in the kindred have lived in the Nagasaki area, but the possibility of earlier non-Japanese ancestry cannot be excluded, particularly in view of the fact that Nagasaki was open to foreign trade for several centuries in the past. The discovery of additional instances of hemoglobin $\mathrm{E}$ would lend support 

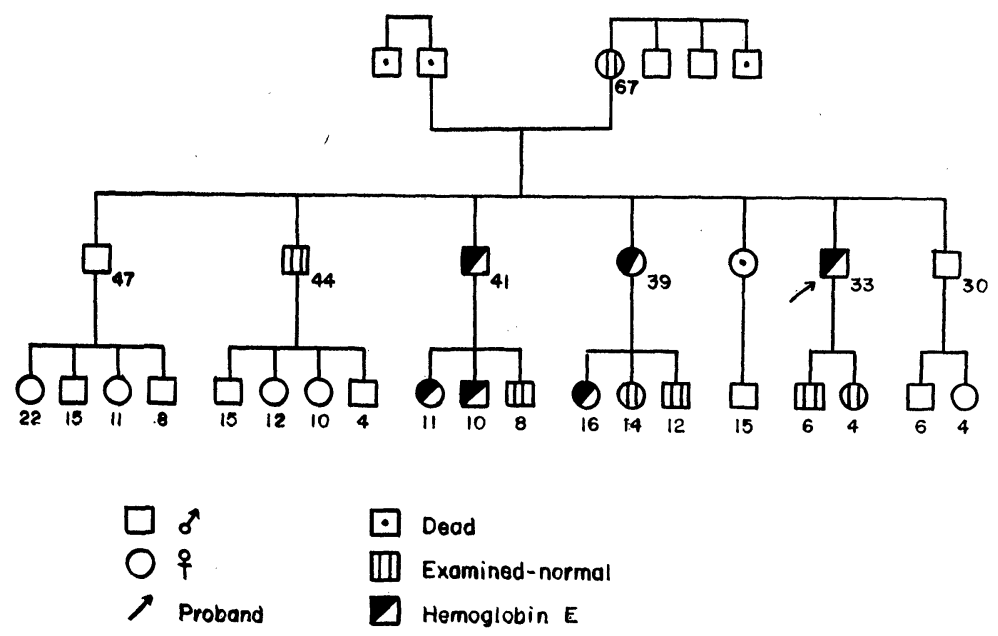

Fig. 5. Family tree. Blank squares (males) and circles (females) refer to the members whose blood was not available for examination.

to the introduction of the trait from elsewhere in Southeast Asia. Nor can the possibility of an independent mutation be definitely excluded at this point, though the probability of such an event seems unlikely. ${ }^{20), 21)}$ For the present no clear choice can be made between this latter explanation and that favoring introduction of the gene into Japan in the remote past.

\section{References}

1) Jonxis, J. H. P., and Delafresnaye, J. F.: Abnormal Hemoglobins. Blackwell Scientific Pub. (Oxford), p. 357, p. 368 (1959).

2) Shibata, S., Iuchi, I., Miyaji, T., and Takeda, I.: Bull. Yamaguchi Med. School, 10, 1 (1963).

3) Ohta, Y., Kawamura, K., and Yamaoka, K.: Proc. Japan Acad., 39, 494 (1963).

4) Shibata, S., and Iuchi, I.: Acta Haem. Jap., 24, 51 (1961).

5) Amano, S., et al (Ed): Nihon-Ketsuekigaku-Zensho (Handbook of Japan Hematology), Maruzen (Tokyo), vol. 2, p. 216 (1963).

6) Dyke, S. C.: Recent Advances in Clinical Pathology. Churchill (London), p. $202(1960)$.

7) Huisman, T. H. J., and Prins, H. K.: Clin. Chim. Acta, 2, 307 (1957).

8) Huisman, T. H. J., Martis, E. A., and Dozy, A.: J. Lab. \& Clin. Med., 52, 312 (1958).

9) Singer, K., Chernoff, A. I., and Singer, L.: Blood, 6, 413 (1951).

10) Shibata, S., Iuchi, I., Ueda, S., Miyaji, T., and Takeda, I.: Acta Haem. Jap., 25, 675 (1962).

11) Take, T.: J. Biochem., 49, 206 (1961).

12) Ingram, V. M.: Biochim. Biophys. Acta, 28, 539 (1958).

13) Baglioni, C.: Biochim. Biophys. Acta, 48, 392 (1961).

14) Brenner, M., und Niederwieser, A.: Experientia, 16, 378 (1961). 
15) Block, R. J., Durrum, E. L., and Zweig, G.: A Manual of Paper Chromatography and Paper Electrophoresis. Academic Press, New York (1955).

16) Braunitzer, G., Hilschmann, N., Rudloff, V., Hilse, K., Liebold, B., and Muller, R.: Nature, 190, 480 (1961).

17) Hunt, J. A., and Ingram, V. M.: Biochim. Biophys. Acta, 49, 520 (1961).

18) Ingram, V. M.: The Hemoglobins in Genetics and Evolution. Columbia University Press, New York, London (1963).

19) Ohta, Y., et al: Paper read at the General Meeting of the Society of Japan Clinical Hematologists, Fukuoka (1964).

20) Komai, T.: Organic Evolution Based on Genetics, Baifukan, Tokyo (1963).

21) Neel, J. V.: The Geography of Hemoglobinopathies in Proceedings of the Conference on Genetic Polymorphisms and Geographic Variations in Disease, ed. by Blumberg, B. S. Grune and Stratton, New York, p. 105 (1961). 